\title{
YAPAY SİNİR AĞLARI İLE TÜRKİYE NET ENERJİ TALEP TAHMİNí
}

\author{
Hüseyin Avni ES*, F. Yeşim KALENDER ${ }^{* *}$, Coşkun HAMZAÇEBİ \\ "Karadeniz Teknik Üniversitesi, Endüstri Mühendisliği Bölümü, Trabzon \\ ${ }^{* *}$ Gazi Üniversitesi, Endüstri Mühendisliği Bölümü, Ankara \\ avnies@ktu.edu.tr,fyesim@gazi.edu.tr, hamzacebi@ktu.edu.tr
}

(Geliş/Received: 26.03.2013; Kabul/Accepted: 17.07.2014)

ÖZET

$\mathrm{Bu}$ çalışmada, yapay sinir ağları (YSA) ile Türkiye net enerji talebi tahmin edilmiştir. Türkiye net enerji talebini tahmin etmek için 1970-2010 yılları arasındaki Gayri Safi Yurtiçi Hâsıla (GSYH), nüfus, ithalat, ihracat, bina yüz ölçümü ve taşıt sayısı değişken verileri YSA modelinin girdisi olarak kullanılmıştır. Kurulan YSA modelinin tahmin performansı, çoklu doğrusal regresyon tekniği ile karşılaştırmalı olarak ortaya konmuştur. Yapılan karşılaş̧ırmalar, YSA'nın üstünlüğünü göstermektedir. Kabul edilebilir ve yüksek doğruluktaki YSA modeli ile 2011-2025 yılları arası Türkiye net enerji talebi tahmin edilmiştir.

Anahtar Kelimeler: YSA, Enerji, Çoklu doğrusal regresyon

\section{FORECASTING THE NET ENERGY DEMAND OF TURKEY BY ARTIFICIAL NEURAL NETWORKS}

\begin{abstract}
In this study, the net energy demand of Turkey has been predicted by artificial neural networks (ANN). In order to forecast net energy demand of Turkey, Gross Domestic Product (GDP), population, import, export, area of the building and vehicles number data was used as input of ANN model. The prediction performance of built ANN model has been demonstrated in comparison with a multiple linear regression technique. The comparisons are shown the superiority of ANN. By using the model which is acceptable and high accuracy, the net energy demand of Turkey has been predicted that between the years of 2011-2025.
\end{abstract}

Key words: ANN, Energy, Multiple linear regressions

\section{GIRISŞ (INTRODUCTION)}

Asya ile Avrupa arasında bir geçiş noktası olan Türkiye, gerek tüketim miktarları gerekse de bir geçiş güzergâhı olması sebebiyle enerji politikaları açısından oldukça önemli bir ülkedir. Türkiye son on yılda önemli değişimler geçirmiştir. 2010 yılı itibarı ile Türkiye nüfusu, 2000 yllına göre $\% 8,7$ oranında artarak 73,7 milyona, yine 2010 yılı itibarı ile cari fiyatlarla GSYH değeri, 2000 yllına göre \%177 oranında artarak 735 milyar \$ seviyesine ulaşmıştır [1].Türkiye'de artan GSYH ve nüfusa paralel olarak enerji tüketimi de artmaktadır. Bu artışlar, Türkiye'yi OECD ülkeleri içerisinde son on ylllık dönemde enerji talep artışının en hızlı gerçekleştiği ülke konumuna getirmiştir [2].Türkiye, dünyada 2000 yılından bu yana elektrik ve doğalgazda Çin'den sonra en fazla talep artışına sahip ikinci büyük ekonomi konumundadır [3]. Bu gelişmeler çerçevesinde artan nüfus, artan sanayileşme ve kentleşme olgularıyla birlikte artan enerji talebini sürdürülebilir şekilde karşılayabilmek amacıyla geleceğe yönelik güvenilir talep tahminleri yapmak oldukça önemlidir.

Tahmin yöntemleri; nitel ve nicel tahmin yöntemleri olmak iki ana gruba ayrılır. Nitel tahmin yöntemi, çalışılan konu üzerinde uzman olan bireyin görüş ve deneyimlerine dayanmaktadır. Nicel tahmin yöntemleri ise matematiksel modellere dayanan yöntemlerdir. Nicel tahmin yöntemleri kendi içerisinde; sebep-sonuç ilişkisi ve zaman serileri analizi olmak üzere iki grubu ayrılır [4]. 
Bu makalede, nicel tahmin metotlarından yapay sinir ağları (YSA) ile Türkiye net enerji talep tahmini çalışması gerçekleştirilmiştir. Literatürde sıkça kullanılan değişkenlere ek olarak net enerji talebine etki eden farklı değişkenler saptanarak YSA modeli kurulmuştur. Kurulan YSA modeli; hem sebep-sonuç ilişkisine dayalı çoklu doğrusal regresyon modeli (ÇDRM) hem de zaman serisine dayalı YSA modeli ile karşılaştırılmıştır.

\section{LITERATÜR ARAŞTIRMASI (LITERATURE REVIEW)}

Enerji talep tahmini için literatürde birçok farklı tahmin teknikleri kullanılmaktadır. Örneğin; zaman serileri [5], gri tahmin [6],regresyon modeli [7], parçacık sürü optimizasyonu [8], geneteik algoritma [9], bulanık mantık [10], yapay sinir ağları [11] vb. tahmin teknikleri kullanılarak enerji talepleri tahmin edilmiştir. Daha geniş enerji talep tahmin modellerine ulaşmak için Suganthi ve Samuel'in [12] çalışması incelenebilir.

Enerji talep tahmini alanında sıklıkla kullanılan tahmin araçlarından biri de YSA'dır. Sözen ve arkadaşları [13,14] Türkiye'nin net enerji tüketimini,Pao [15] Tayvan'ın elektrik enerji tüketimini, Kavaklıŏlu ve arkadaşları [16] Türkiye'nin elektrik enerji tüketimini, Geem ve Roper [17] Güney Kore'nin enerji talebini, Ekonomou [18] Yunanistan'ın toplam enerji talebini, Limanond ve arkadaşları [19] Tayland'ın ulaştırma enerji talebini, Kankal ve arkadaşları [20]Türkiye'nin genel enerji tüketimini, Geem [21] Güney Kore'nin ulaştırma enerji talebini ve Bilgili ve arkadaşları [22] Türkiye'deki konut ve sanayi sektörlerinin enerji tüketimini tahmin etmek için YSA'nı kullanmışlardır. YSA ile gerçekleştirilen enerji talep tahmin çalışmaları Tablo 1'de özet halinde sunulmuştur.
Literatürde enerji talep tahminiyle ilgili benzer çalışmalar mevcuttur. Çeşitli tahmin teknikleri kullanılarak Türkiye'de gerçekleştirilen enerji talep tahmini çalışmaları Tablo 2'de özetlenmiştir.

\section{YÖNTEMLER (METHODS)}

\subsection{Yapay Sinir Ağları (Artificial Neural Networks)}

YSA insan idrakinin ve biyolojik sinirlerin matematiksel modelinin genelleştirilmesidir [43]. YSA, biyolojik sinir hücresinden esinlenerek geliştirilen yapay sinir hücrelerinin birleşmesiyle meydana gelmektedir. YSA'nın; doğrusal olmayan yapıları modelleyebilmesi, paralel dağılmış yapısı, ögrenme ve genelleme yapabilme yeteneği, farklı problemler için uyarlanabilirliği ve hata toleransına sahip olması en önemli özelliklerindendir [4].

YSA girdi ve çıktı değişkenleri arasında herhangi bir ön bilgiye ihtiyaç duymamaktadır. Ağa girdi bilgileri ve bilgilere karşılık gelen çıktı bilgileri verilerek ağın girdi-çıktı değişkeni arasındaki ilişkiyi öğrenmesi sağlanır [24]. Bu öğrenme işlemi danışmanlı öğrenme olarak adlandırılmaktadır. Mevcut problemin çözümünde danışmanlı öğrenme metodundan geri yayılım algoritması kullanılmıştır. Bir yapay sinir ağının geri yayılım algoritmasıylaöğrenmesi; ileri ve geriye doğru hesaplama olmak üzere iki aşamadan oluşur. İleriye doğru hesaplama işleminde ağa gelen girdi değerleri ağırlık matrisleriyle işleme girerek çıktı değeri hesaplanır. Daha sonra ağın ürettiği çıktı değeri ile gerçek değer arasındaki hata değerinin minimize edilmesi esas alınarak ağın geriye doğru yayılımı ile birlikte ağ ağırlıkları yeniden düzenlenir. $\mathrm{Bu}$ işlem, ağın istenen çıktıyı ürettiği zamana kadar devam etmektedir.

Tablo 1. YSA ile gerçekleştirilen enerji talep tahmini çalışmaları(Studies on energy demand forecasting by ANN)

\begin{tabular}{|c|c|c|c|c|}
\hline Yazarlar & Değişkenler & Veri Yılı & Enerji Türü & Tahmin Dönemi \\
\hline Sözen ve arkadaşları [13] & $\begin{array}{l}\text { Nüfus, brüt üretim, kurulu kapasite, } \\
\text { ithalat, ihracat }\end{array}$ & $1975-2003$ & Enerji talebi & Model kuruldu \\
\hline Sözen ve Arcaklığlu [14] & Nüfus, ekonomik göstergeler & $1968-2005$ & Enerji talebi & Model kuruldu \\
\hline Pao [15] & Milli gelir, GSYH, tüketici fiyat endeksi & $\begin{array}{l}\text { Ocak 1990- } \\
\text { Aralık } 2002\end{array}$ & Elektrik enerji talebi & Model kuruldu \\
\hline $\begin{array}{l}\text { Kavaklığlu ve arkadaşları } \\
\text { [16] }\end{array}$ & GSMH, nüfus, ithalat ve ihracat & $1975-2006$ & Elektrik enerji talebi & $2007-2027$ \\
\hline Gem ve Roper [17] & GSYH, nüfus, ithalat, ihracat & $1980-2007$ & Toplam enerji talebi & $2008-2025$ \\
\hline Ekonomou [18] & $\begin{array}{l}\text { Sicaklık, kurulu güç kapasitesi, GSYH, } \\
\text { yerleşik elektrik tüketimi }\end{array}$ & $1992-2008$ & Toplam enerji talebi & $2010,2012,2015$ \\
\hline Limanond ve arkadaşları [19] & GSYH, nüfus ve kayıtlı araç sayıları & $1989-2008$ & $\begin{array}{l}\text { Ulaştırma enerji } \\
\text { talebi }\end{array}$ & $2010-2030$ \\
\hline Kankal ve arkadaşları [20] & GSYH, nüfus, ithalat, ihracat, iş & $1980-2007$ & Genel Enerji talebi & $2008-2014$ \\
\hline Geem [21] & $\begin{array}{l}\text { Petrol fiyatları, kayıtlı araç sayısı, yolcu } \\
\text { taşıma miktarı }\end{array}$ & $1990-2008$ & $\begin{array}{l}\text { Ulaştırma enerji } \\
\text { talebi }\end{array}$ & $2008-2025$ \\
\hline Bilgili ve arkadaşları [22] & $\begin{array}{l}\text { Kurulu kapasite, brüt elektriküretimi, } \\
\text { nüfus ve toplam abone sayısı }\end{array}$ & $1990-2007$ & Elektrik enerji talebi & $2008-2015$ \\
\hline
\end{tabular}


Tablo 2. Türkiye'de enerji talep tahmini çalışmaları(Studies on energy demand forecasting of Turkey)

\begin{tabular}{|c|c|c|c|c|}
\hline Yazarlar & Tahmin Yöntemi & $\begin{array}{l}\text { Veri Yıl } \\
\text { Aralığı }\end{array}$ & Enerji Türü & Tahmin yılı \\
\hline Ceylan ve Öztürk [23] & GA & $1970-2001$ & Toplam Enerji & $2002-2025$ \\
\hline Hamzaçebi ve Kutay [24] & YSA & $1970-2002$ & Elektrik enerjisi & $2003-2010$ \\
\hline Sözen ve arkadaşları [25] & YSA & $2000-2002$ & Solar enerji & Model kuruldu \\
\hline Öztürk ve arkadaşları [26] & GA & $1990-2000$ & Kullanılabilir petrol & $2001-2020$ \\
\hline Sözen ve arkadaşları [13] & YSA & 1975-2003 & Toplam enerji & Model kuruldu \\
\hline Haldenbilen ve Ceylan [27] & GA & $1970-2000$ & Ulaştırma enerji & $2001-2020$ \\
\hline Ediger ve arkadaşları [28] & ARIMA & $1950-2003$ & Fosil yakıtlar & $2004-2028$ \\
\hline Murat ve Ceylan [29] & YSA & $1970-2001$ & Ulaştırma enerji & $2004-2020$ \\
\hline Akay ve Atak [6] & Gri Tahmin & 1970-2004 & Elektrik enerjisi & 2006-2015 \\
\hline Ediger ve Akar [30] & ARIMA & 1950-2004 & Toplam enerji & $2005-2020$ \\
\hline Sözen ve Arcaklığlu [15] & YSA & $1968-2005$ & Toplam enerji & Model kuruldu \\
\hline Erdoğdu [31] & ARIMA & 1984-2004 & Elektrik enerjisi & $2005-2014$ \\
\hline Hamzaçebi [11] & YSA & 1970-2004 & Elektrik enerjisi & $2005-2020$ \\
\hline Toksarı [32] & $\mathrm{ACO}$ & $1979-2005$ & Toplam Enerji & $2006-2025$ \\
\hline Canyurt ve Öztürk [33] & GA & $1975-2006$ & Fosil yakıt & $2007-2020$ \\
\hline Ünler [34] & PSO & $1979-2005$ & Toplam enerji & $2006-2025$ \\
\hline Kavaklığlu ve arkadaşları [16] & YSA & $1975-2006$ & Elektrik enerjisi & $2007-2027$ \\
\hline Toksarı [35] & $\mathrm{ACO}$ & $1979-2006$ & Elektrik enerjisi & $2007-2025$ \\
\hline Çınar ve arkadaşları [36] & GA & $1970-2006$ & Hidroelektrik & $2007-2012$ \\
\hline Demirel ve arkadaşları [37] & ANFIS & $1970-2005$ & Elektrik enerjisi & $2006-2010$ \\
\hline Erdoğdu [38] & ARIMA & $1987-2007$ & Doğal gaz & $2008-2030$ \\
\hline Küçükali ve Barış [10] & Bulanık mantık & $1980-2008$ & Elektrik enerjisi & $2009-2014$ \\
\hline Filik ve arkadaşları [39] & Matematiksel model & $1982-2007$ & Elektrik enerjisi & Model kuruldu \\
\hline Kankal ve arkadaşları [20] & YSA, Regresyon & $1980-2007$ & Toplam enerji & $2008-2014$ \\
\hline Kavaklığlu [40] & Destek vektör regresyon modeli & $1975-2006$ & Elektrik enerjisi & $2007-2026$ \\
\hline Bilgili ve arkadaşları [22] & YSA, Regresyon & 1990-2007 & Elektrik enerjisi & $2008-2015$ \\
\hline Dilaver ve Hunt [41] & Yapısal zaman serileri & $1960-2008$ & Elektrik enerjisi & $2009-2020$ \\
\hline Kıran ve arkadaşları [42] & Hibrit model (PSO ve ACO) & $1979-2005$ & Toplam Enerji & $2006-2025$ \\
\hline
\end{tabular}

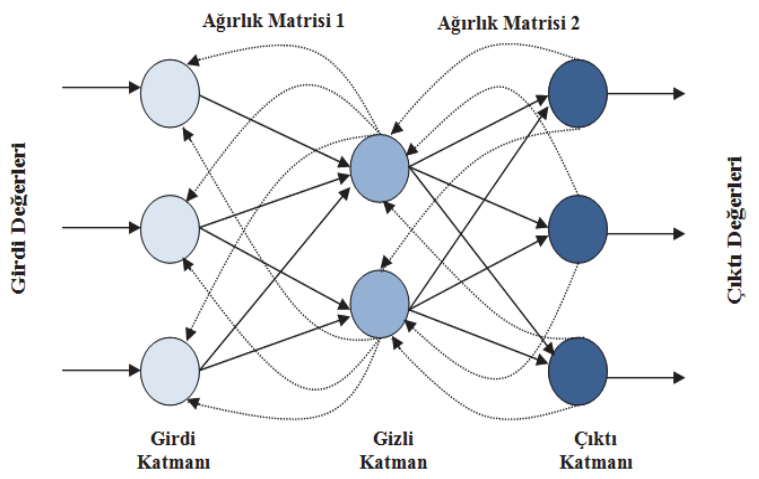

Şekil 1.İleri beslemeli geri yayılım yapay sinir ağ yap1s1(Feed forward back propagation neural network architecture)

YSA, hem sebep-sonuç ilişkisine dayalı hem de zaman serisine dayalı tahmin yöntemlerinde kullanılabilmektedir. Sebep sonuç ilişkisine dayanan bir tahmin problemi için YSA'nın girdileri bağımsız değişkeni ifade etmektedir. Çıktısı ise bağımlı değişkendir. YSA tarafından belirlenen doğrusal olmayan fonksiyonel iliş̧i Eşitlik 1'deki gibi yazılabilir [4].

$Y=f\left(x_{1}, x_{2}, \ldots, x_{n}\right)$
Yukarıdaki eşitlikte $x_{1}, x_{2}, \ldots, x_{n}, \mathrm{n}$ adet bağımsız değişkeni, $\quad \mathrm{Y}$ ise bağımlı değişkeni ifade etmektedir.Zaman serisine dayalı bir tahmin problemi için YSA'nın girdileri veri serisinin geçmiș gözlem değerlerinden oluşurken, çıktı gelecekteki tahmin değerini temsil eder. YSA tarafindan belirlenen doğrusal olmayan ilișki Eşitlik 2'deki gibi yazılabilir [4].

$Y_{t+1}=f\left(Y_{t}, Y_{t-1}, \ldots, Y_{t-n}\right)$

\section{2. Çoklu Doğrusal Regresyon Modeli(Multiple Linear Regression Model)}

Regresyon modelinde, etkileyen değişkenlere açıklayıcı değişken (bağımsız değişken), etkilenen değişkene de açıklanan değişken (bağımlı değişken) adı verilir. Y bağımlı değişken; $x_{1}, x_{2}, \ldots, x_{n}$ bağımsız değişkenler olmak üzere değişkenler arasındaki sebep-sonuç ilişkisini matematiksel bir model olarak ortaya koyan yönteme çoklu doğrusal regresyon modeli adı verilir. Çoklu doğrusal regresyon modeli Eşitlik 3'teki gibi yazılabilir. Burada $b_{0}, b_{1}, b_{2}$, $\ldots b_{n}$ her bir bağımsız değişkenin bağımlı değişken üzerindeki etkisini göstermektedir.

$Y=b_{0}+b_{1} X_{1}+b_{2} X_{2}+\ldots+b_{n} X_{n}$ 


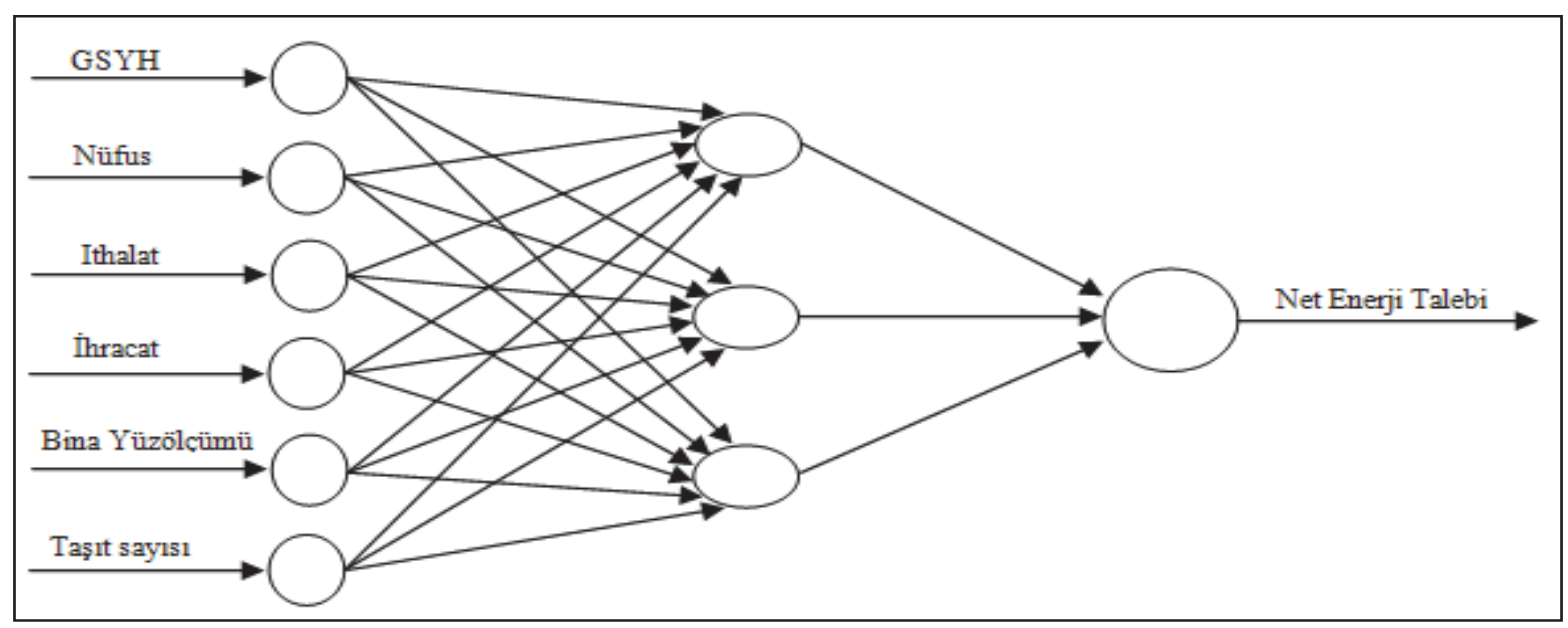

Şekil 2.Türkiye net enerji talebi için SSYSA-1 yapısı(SSYSA-1 architecture for Turkey net energy demand)

\section{UYGULAMA (APPLICATION)}

\subsection{Sebep-sonuç İlişkisine Dayalı YSA Uygulaması} (Application of ANN based on Cause-affect Relationship)

Literatürde sebep-sonuç ilişkisine dayanan tahmin yöntemleri ile yapılan çalışmalarda kullanılan bağımsız değişkenlerin farklılık gösterdiği görülmektedir. Enerji talebi için GSYH, nüfus, ithalat ve ihracat gibi değişkenler birçok çalışmada kullanılan ortak değişkenlerdir $[16,17,23,32]$. Bu çalışmada, YSA ile kurulacak model ile net enerji talebini güvenilir ve kararlı bir şekilde tahmin edebilmek için, modele eklenebilecek bağımsız değişkenler araştırılmış ve yeterli sayıdaki geçmiş gözlem değerlerine ulaşılan bina yüzölçümü ve taşıt sayısı değişkenleri bağımlı değişken olarak modele eklenmiştir. Çalışmada üç farklı sebep sonuç ilişkisine dayalı YSA (SSYSA) modeli kullanılmıştır. SSYSA1 modelinin ă̆ yapısı Şekil 2'de gösterilmektedir.

1970'den 2010 yılına kadar resmi kaynaklardan [1,3] elde edilen bağımsız ve bağımlı değişkenler için veriler toplandıktan sonra MATLAB ".m" dosyası oluşturularak sebep-sonuç ilişkisine dayalı yapay sinir ağları (SSYSA-1) model kurulumu gerçekleştirilmiştir. Eldeki verilerin \%70'i eğitim, \%15'i doğrulama ve \%15'i test seti için kullanılmıştır [44]. Hem girdi hem çıktı verileri basit normalizasyon işlemiyle $[0,1]$ aralığına dönüştürülmüştür.

Literatürdeki çalışmalarda tek gizli katman sayısı başarılı sonuçlar elde etmede yeterli olduğundan tek gizli katman tercih edilmiştir [44]. Gizli katmandaki nöron sayısı ise, eğitim ve doğrulama kümeleri için en iyi sonucu verecek şekilde deneme yanılma yöntemiyle belirlenmiştir. Kurulan yapay sinir ağları modelinde gizli katman aktivasyon fonksiyonu olarak sigmoid aktivasyon fonksiyonu kullanılmıştır. Çıktı katmanı aktivasyon fonksiyonu olarak ise doğrusal aktivasyon fonksiyonu (özdeşlik fonksiyonu) kullanılmıştır. Öğrenme metodu için en iyi sonucu veren yöntem araştırılmış ve Bayesyen düzeltmeye dayalı geri yayılım algoritması kullanılmıştır.

Çalışmada hata kareleri toplamı (HKT) ve ortalama mutlak yüzde hata $(\mathrm{OMYH})$ performans ölçütleri kullanılmıştır. Aşağıdaki eşitlikler performans ölçütlerinin hesaplanışını göstermektedir.

Hata Kareleri Toplamı $(\mathrm{HKT})=\sum_{i=1}^{n} e_{i}^{2}$

Ort. Mutlak Yüzde Hata(OMYH) $=\frac{1}{n} \sum_{i=1}^{n}\left|\frac{e_{i}}{Y_{i}}\right| * 100(5)$

Burada, $e_{i}$ i.hata (gerçek gözlem değeri ile tahmin değeri arasındaki fark) değerini, $Y_{i}$, i. gözlem değerini, $n$ veri sayısını ifade etmektedir. Her iki performans ölçütünün de düşük değerleri daha iyi tahmini göstermektedir.Literatürde,OMYH’nın $\quad \% 10$ 'dan küçük olması durumunda başarılı bir tahmin gerçekleştirilmiş olduğu belirtilmektedir [45].

Ağın eğitimi sırasında hata performans fonksiyonu olarak HKT ve kurulan modelin başarısını karşılaştırma amacı ile de OMYH performans ölçütü dikkate alınmıştır.Model 2000 iterasyon için eğitilmiş ve bu eğitime ilişkin HKT fonksiyonunun grafiği Şekil 3'de görülmektedir. Model en iyi performansı 304. iterasyonda yakalamıştır.

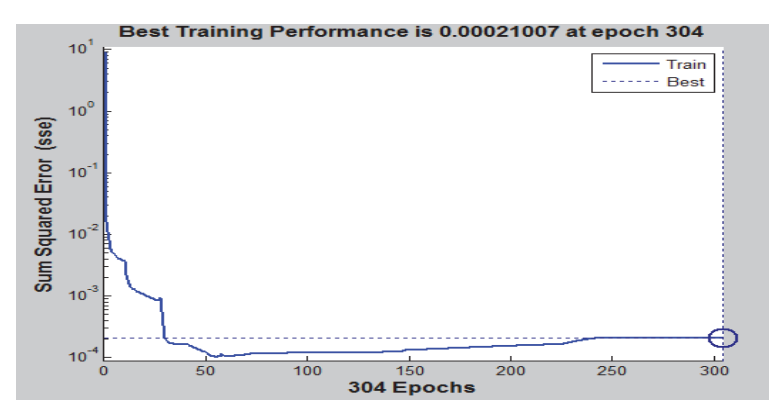

Şekil 3.Eğitim kümesi HKT grafiği (Graph of SSE for training set) 
Modelin OMYH değerleri Tablo 3'de verilmiştir. Eğitim kümesi için elde edilen \%1,7'lik hata değeri, eğitimin oldukça başarılı bir şekilde gerçekleştiğini göstermektedir. Ayrıca doğrulama kümesi için \%4,92'lik değerde ağın doğru bir şekilde eğitildiğini, ezberleme yapmadığını göstermektedir. Test kümesinde elde edilen \%1,75'lik OMYH değeri modelin başarılı tahminler gerçekleştirebilecek düzeyde olduğunu göstermektedir.

Tablo 3.SSYSA modeli OMYH değeri(MAPE results for SSYSA model)

\begin{tabular}{|c|c|c|}
\hline & Yıllar & OMYH \\
\hline Ĕgitim kümesi & $1970-1995$ & $1,70 \%$ \\
\hline Doğrulama kümesi & $1996-2003$ & $4,92 \%$ \\
\hline Test kümesi & $2004-2010$ & $1,75 \%$ \\
\hline
\end{tabular}

Ağın eğitilmesinden sonra elde edilen ağırlık değerleri; eğitim, doğrulama ve test kümelerinin tahmini için kullanılmış ve elde edilen sonuçlar gerçek değerlerle karşılaştırmalı olarak Şekil 4'te sunulmuştur. Şekil 4'te görüldüğü üzere modelin eğitim, doğrulama ve test kümesi için elde ettiği tahmin değerleri gerçek değerlere oldukça yakın bir seyir izlemektedir.

Literatürden farklı olarak, SSYSA-1 modeline girdi değişkeni olarak eklenen bina yüzölçümü ve taşıt sayısı değişkenlerinin tahmin performansına katkısını görebilmek amaciyla sadece GSYH, nüfus, ithalat ve ihracat değişkenleri kullanılarak SSYSA-2 adı verilen yeni bir YSA modeli kurulmuştur. Model kurma aşamasında tek gizli katman tercih edilmiştir. Deneme yanılma yöntemiyle en iyi parametreler belirlenmiştir. Gizli katmanda sigmoid, çıktı katmanında özdeşlik fonksiyonu kullanılmıştır. Öğrenme yöntemi olarak Bayesyen düzeltmeye dayalı geri yayılım algoritması kullanılmıştır. Kurulan SSYSA-2 modeli ile SSYSA1 modelinin OMYH değerleri Tablo 4'te karşılaştırmalı olarak verilmiştir.

Tablo 4'te görüldüğü üzere her iki modelin doğrulama kümesi değerleri dikkate alındığında ezberleme sorunu görülmemektedir. SSYSA-1 modeli, SSYSA-2 modeline göre daha başarılı bir eğitim gerçekleştirerek elde ettiği ağırlık değerleri ile test kümesini daha az hata ile tahmin etmiştir. Böylece, SSYSA-2 modelinde kullanılan değişkenlere ek olarak SSYSA-1 modeline ilave edilen bina yüz ölçümü ve taşıt sayısı değişkenleri enerji modelini açıklamada önemli katkı sağladığ1 söylenebilmektedir.

Tablo 4. OMYH değerleri (MAPE values)

\begin{tabular}{|c|c|c|c|}
\hline \multirow{2}{*}{ Yıllar } & SSYSA-2 & SSYSA-1 \\
\cline { 3 - 4 } & & OMYH & OMYH \\
\hline Ĕgitim kümesi & $1970-1995$ & $1,97 \%$ & $1,70 \%$ \\
\hline Doğrulama kümesi & $1996-2003$ & $3,61 \%$ & $4,92 \%$ \\
\hline Test kümesi & $2004-2010$ & $2,75 \%$ & $1,75 \%$ \\
\hline
\end{tabular}

\subsection{Zaman Serisine Dayalı Yapay Sinir} A ğları(Artificial Neural Networks based on Time Series)

Zaman serileri tahmininde ağın girdisi ve çıktısı seriye ait gözlem değerleridir. Girdi nöronu sayısı, seri değerinin kaç adet geçmiş gözlem değeri ile ilişkilendirileceğine göre değişir.Çalışmada girdi nöronu sayıları için denemeler yapılmış ve net enerji talebinin tahmininde en uygun modelin 3 girdi nöronlu olduğu tespit edilmiştir. Bir sonraki dönemi tahmin edebilmek için üç dönem önceki net enerji talep değerleri dikkate alınarak YSA yapısı oluşturulmuştur. Zaman serisine dayalı yapay sinir ağları (ZSYSA) yapısı Şekil 5'te gösterilmektedir.

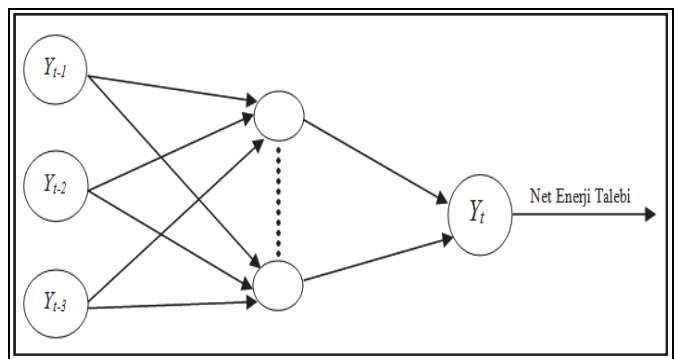

Şekil 5.ZSYSA ă̆ yapısı (ZSYSA network architecture)

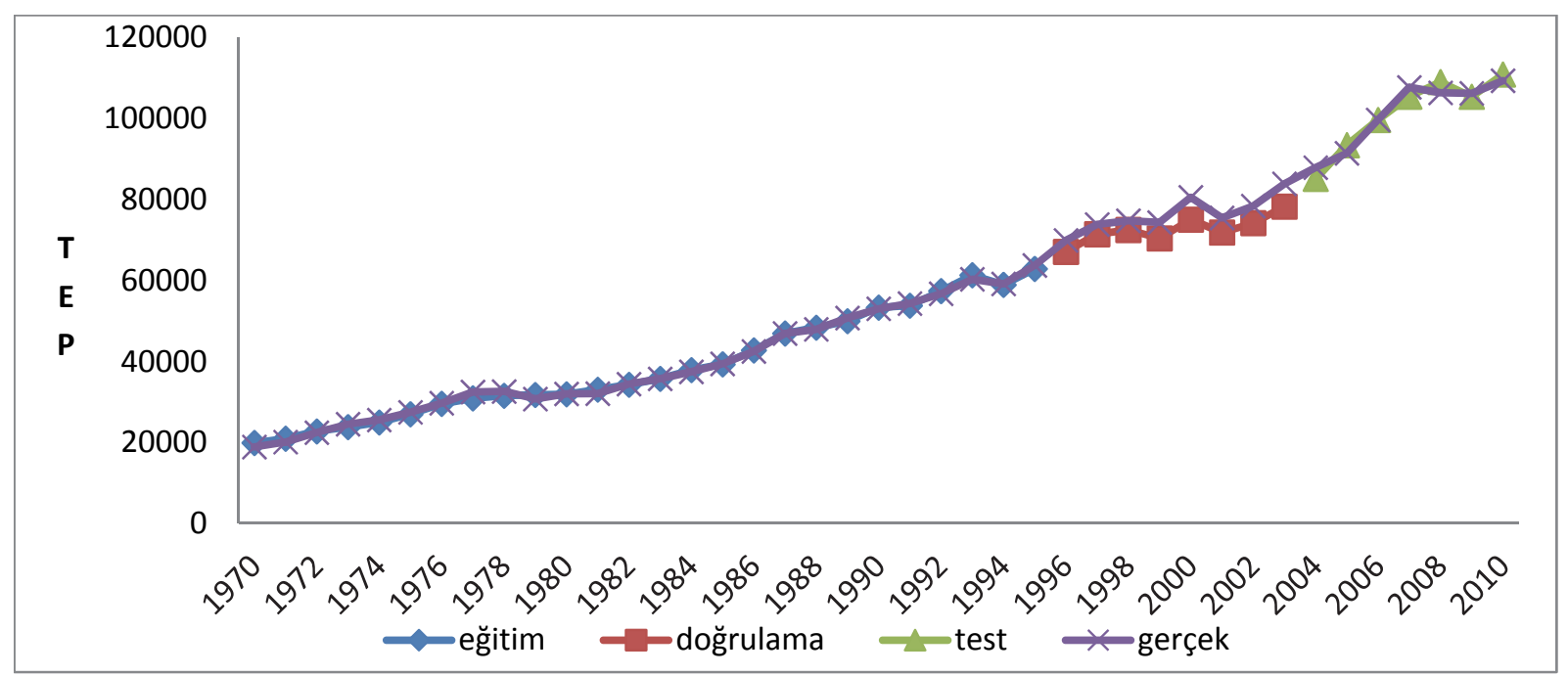

Şekil 4. Gerçek değerler ve SSYSA tahmin değerleri (Real values and SSYSA forecasting values) 
ZSYSA MATLAB'da “.m” dosyası oluşturularak kodlanmıştır. ZSYSA modelini, SSYSA-1 modeli ile karşılaştırabilmek için aynı veri setleri ile çalışılmıştır. Model kurma aşamasında tek gizli katman tercih edilmiştir. Deneme yanılma yöntemiyle en iyi parametreler belirlenmiştir. Gizli katmanda sigmoid, çıktı katmanında özdeşlik fonksiyonu kullanılmıştır. Öğrenme yöntemi olarak Bayesyen düzeltmeye dayalı geri yayılım algoritması kullanılmıştır. Kurulan ZSYSA modelinden elde edilen test kümesi mutlak yüzde hata (MYH) değerleri ile SSYSA-1 modelinden elde edilen MYH değerleri Tablo 5'te karşılaştırılmıştır. Tablo 5'de her iki model için ortalama mutlak yüzde hata (OMYH) değerlerine bakıldığında SSYSA-1 modelinin ZSYSA modeline göre oldukça düşük hata değerine sahip olduğu görülmektedir. Böylece SSYSA-1 modelinin daha iyi bir model olduğu ve daha başarılı tahminler gerçekleştirebileceği söylenebilmektedir.

Tablo 5. ZSYSA ve SSYSA MYH değerleri (ZSYSA and SSYSA-1 APE values)

\begin{tabular}{|c|c|c|}
\hline Yıllar & $\begin{array}{c}\text { ZSYSA Mutlak Yüzde } \\
\text { Hata Değerleri }\end{array}$ & $\begin{array}{c}\text { SSYSA-1 Mutlak } \\
\text { Yüzde Hata değerleri }\end{array}$ \\
\hline 2004 & $2,06 \%$ & $3,18 \%$ \\
\hline 2005 & $0,92 \%$ & $2,20 \%$ \\
\hline 2006 & $5,40 \%$ & $0,01 \%$ \\
\hline 2007 & $5,65 \%$ & $2,15 \%$ \\
\hline 2008 & $3,44 \%$ & $2,52 \%$ \\
\hline 2009 & $4,29 \%$ & $0,78 \%$ \\
\hline 2010 & $0,68 \%$ & $1,40 \%$ \\
\hline OMYH & $\mathbf{3 , 2 1} \%$ & $\mathbf{1 , 7 5} \%$ \\
\hline
\end{tabular}

Tablo 6.Minitab analiz sonuçları (Minitab analysis results)

\begin{tabular}{|c|c|c|c|c|c|}
\hline Tahmin değişkeni & Katsayı & $\begin{array}{c}\text { Standart } \\
\text { Hata }\end{array}$ & $\mathbf{T}$ & $\mathbf{P}$ & VIF \\
\hline Sabit & $-51,55$ & 12,76 & $-4,04$ & 0,001 & \\
\hline Nüfus & 0,69332 & 0,07606 & 9,12 & 0,000 & 6,971 \\
\hline Bina yüz ölçümü & 0,6896 & 0,1266 & 5,45 & 0,000 & 9,652 \\
\hline Taşıt sayısı & 0,39126 & 0,07318 & 5,35 & 0,000 & 6,061 \\
\hline $\mathrm{S}=10,5121$ & \multicolumn{2}{|c|}{ R-kare $=99,2 \%$} & & & R-kare (düzeltilmiş) $=99,1 \%$ \\
\hline \multicolumn{6}{|c|}{ Varyans Analizi } \\
\hline Kaynak & DF & SS & MS & $\mathbf{F}$ & $\mathbf{P}$ \\
\hline Regresyon & 3 & 303581 & 101194 & 915,74 & 0,000 \\
\hline
\end{tabular}

\section{3. Çoklu Doğrusal Regresyon Modeli (Multiple Linear Regression Model)}

SSYSA-1'de kullanılan girdi değişkenleri çoklu doğrusal regresyon modelinde (ÇDRM) bağımsız değişkenler olarak, SSYSA-1 modelinde kullanılan çıktı değişkeni ise ÇDRM'de bağımlı değişken olarak kullanılmıştır. SSYSA-1 modelindeki eğitim kümesi bağımsız değişken verileri MiNiTAB programında analiz edilerek ÇDRM kurulmuştur. Ancak kurulan regresyon modelinin, istatistiksel anlamlılığa sahip olmadığı ve bağımsız değişkenler arasında çoklu doğrusal bağlantı ve gözlem değerleri arasında otokorelasyon olmaması varsayımlarını sağlamadığı görülmüştür. $\mathrm{Bu}$ sebeple modelin müsaade ettiği bağımsız değişkenler belirlenmiş ve GSYH, ithalat ve ihracat bağımsız değişkenleri modelden çıkarılmıştır. Sonra modele tam kare transformasyonu uygulanmış ve çoklu doğrusal bağlantı problemi ortadan kaldırılarak model uygun hale getirilmiştir. 19701995 yılları arasındaki nüfus, bina yüz ölçümü ve taşıt sayısı bağımsız değişken verileri Minitab programında analiz edilmiş ve sonuçlar Tablo 6'da verilmiştir.

Modelin bağımsız değişkenlerinin her biri için $\mathrm{p}<$ 0,05 olduğundan, katsayıların $\% 95$ güven düzeyinde istatistiksel olarak anlamlı olduğu sonucuna ulaşılmıştır. Modelin açıklayıcılığı \%99,2 olarak elde edilmiştir. $\mathrm{F}$ testi sonucunda $(\mathrm{p}<0,05)$, modelin geçerli bir model olduğu görülmektedir. Modeldeki bağımsız değişkenler arasında çoklu doğrusal

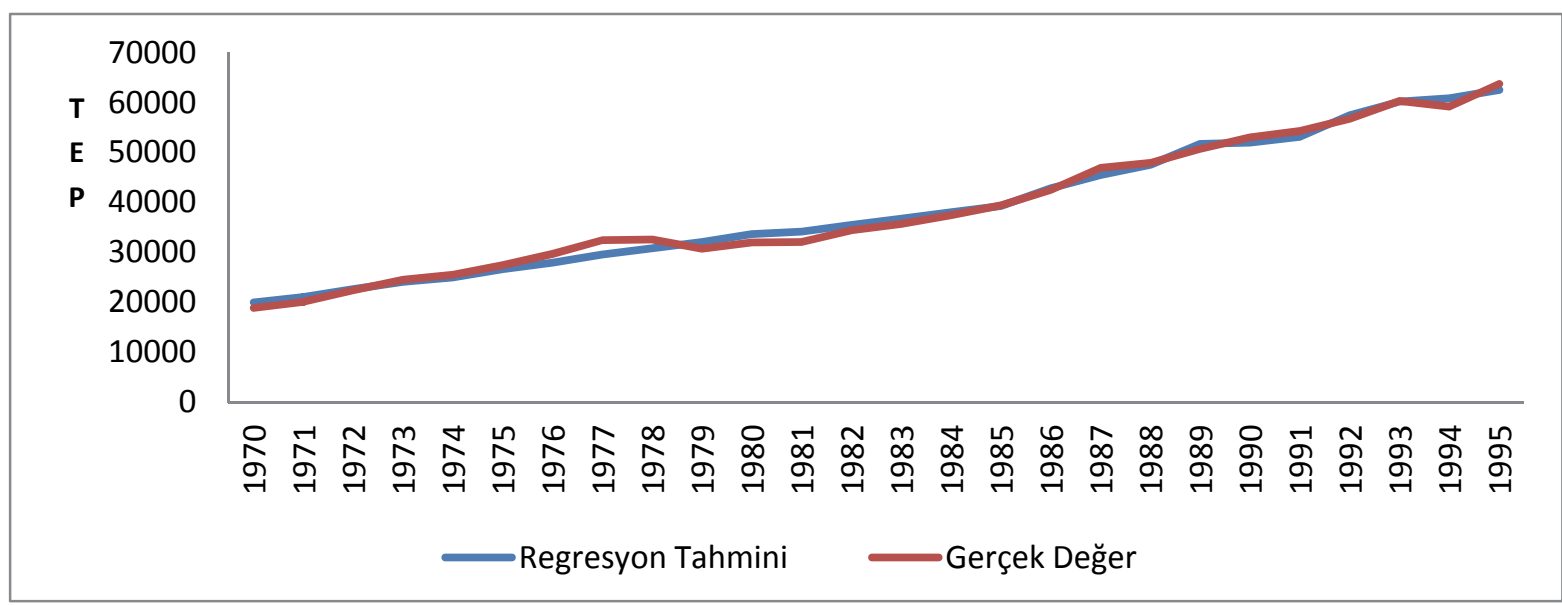

Şekil 6. ÇDRM hata payları grafiği(Graph of ÇDRM error margin) 
bağlantının olup olmadığını test etmek için varyans artış faktörü (VIF) değerleri dikkate alınmıştır. VIF değerleri 10'dan küçük olduğundan bağımsız değişkenler arasında çoklu bağlantı yani bağımlılık yoktur. Daha sonra tahmin hataları arasında bağımlılık olup olmadığı araştırılmıştır. Bu nedenle Durbin-Watson istatistiği kullanılmıştır. DurbinWatson test istatistiğine göre tahmin hataları arasında bağımlılık problemi yoktur. Modelin hata paylarına ilişkin grafiği de Şekil 6'de görüldüğü gibidir.Şekil 6'da görüldüğü üzere, gerçekleşen ve tahmin edilen net enerji talep değerlerinin birbirine örtüşen yapıda olduğu ve aralarındaki sapmaların aşırılık göstermediği görülmektedir. Bu nedenle elde edilen ÇDRM'nin tahmin için uygun olduğu görülmüştür.

\subsection{Bulgular ve Karşılaştırma(Results and Comparison)}

ÇDRM'de, net enerji talebini tahmin etmek için nüfus, bina yüz ölçümü ve taşıt sayısı değişkenleri kullanılmıştır. ÇDRM'nin sonuçlarını SSYSA-1 sonuçları ile özdeş bir şekilde karşılaştırabilmek için, ÇDRM'de kullanılan aynı değişkenlerle, sebep-sonuç ilişkisine dayalı yeni bir yapay sinir ağı (SSYSA-3) modeli kurularak tahmin yapılmıştır. Model kurma aşamasında tek gizli katman tercih edilmiştir. Deneme yanılma yöntemiyle en iyi parametreler belirlenmiştir. Gizli katmanda sigmoid, çıktı katmanında özdeşlik fonksiyonu kullanılmıştır. Öğrenme yöntemi olarak Bayesyen düzeltmeye dayalı geri yayılım algoritması kullanılmıştır. Kurulan SSYSA-3 modeli ile ÇDRM'nin performans karşılaştırılmaları Tablo 7'de verilmiştir.

Tablo 7'de görüldüğü üzere SSYSA-3 modeli OMYH değeri ÇDRM'ne göre daha düşüktür. SSYSA-3 modelinde kullanılan değişkenler regresyon modelinin izin verdiği değişkenlerle aynı olmasına rağmen, SSYSA-3 modelinin daha başarılı sonuçlar verdiği ve daha üstün olduğu görülmüştür. Buradan hareketle çalışma başlangıcındaki SSYSA-1 modelinde, SSYSA-3'te kullanılan (nüfus, bina yüz ölçümü ve taşıt sayısı) bağımsız değişkenlere ek olarak GSYH, ithalat ve ihracat değişkenleri de kullanılmıştır. Elde edilen bulgulara göre, SSYSA-1 modelinin, SSYSA-3 modeline oranla daha başarılı sonuçlar verdiği görülmüştür. Tablo 8'de her iki model için test kümesine ait OMYH değerleri verilmiştir. Tablo 8'deki sonuçlara göre, SSYSA-1 modelinde kullanılan bağımsız değişkenlerin doğru ve güvenilir sonuç elde etmede katkısı olduğu görülmektedir.

Tablo 8. OMYH değerleri (MAPE values)

\begin{tabular}{|c|c|c|}
\hline & \multicolumn{2}{|c|}{ OMYH } \\
\hline Test Kümesi & SSYSA-1 & SSYSA-3 \\
\hline $2004-2010$ & $1,75 \%$ & $4,21 \%$ \\
\hline
\end{tabular}

\subsection{Tahmin (Forecasting)}

Yapılan karşılaştırmalar, en iyi tahmin aracı olarak SSYSA-1 modelini gösterdiğinden, geleceğe ilişkin tahminler bu model ile yapılmıştır. Gelecekteki net enerji talebini tahmin edebilmek için SSYSA-1 modelinde kullanılan bağımsız değişkenlerin gelecekteki değerlerinin bilinmesi gerekmektedir. $\mathrm{Bu}$ nedenle muhtemel senaryolar üretilerek bu değerler elde edilmiş ve tahmin çalışması gerçekleştirilmiştir. Bağımsız değişken değerlerinde meydana gelebilecek artış oranları, düşük, beklenen ve yüksek senaryo olmak üzere eski veriler üzerinde yapılan istatistiksel analizler sonucunda belirlenmiştir. Nüfus verileri için Türkiye İstatistik Kurumunun yıl ortası nüfus tahmin değerleri kullanılmıştır. Belirlenen bu senaryolara ilişkin değerler Tablo 9'de verilmiştir.

Çalışmada kurulan SSYSA-1 modeline düşük, beklenen ve yüksek senaryolar uygulanarak 20112025 yılları arasındaki net enerji talebi tahmin edilmiştir. Bu tahmin değerleri Tablo 10'da verilmiştir. Senaryolara göre tahmin grafiği ise Şekil 7'de görülmektedir.

Tablo 7. ÇDRM ve SSYSA-3 tahmin değerleri ve OMYH değerleri (ÇDRM and SSYSA-3 forecasting values and MAPE values)

\begin{tabular}{|c|c|c|c|c|c|}
\hline \multirow[b]{2}{*}{ Yillar } & \multirow[b]{2}{*}{ Gercek (TEP) } & \multicolumn{2}{|c|}{ TAHMİN } & \multicolumn{2}{|c|}{ MYH } \\
\hline & & ÇDRM (TEP) & SSYSA-3 (TEP) & ÇDRM & SSYSA-3 \\
\hline 2004 & 87818 & 76455 & 87748 & $12,94 \%$ & $0,08 \%$ \\
\hline 2005 & 91362 & 87093 & 93805 & $4,67 \%$ & $2,67 \%$ \\
\hline 2006 & 99590 & 94552 & 93318 & $5,06 \%$ & $6,30 \%$ \\
\hline 2007 & 107625 & 100771 & 94248 & $6,37 \%$ & $12,43 \%$ \\
\hline 2008 & 106273 & 103419 & 104878 & $2,69 \%$ & $1,31 \%$ \\
\hline 2009 & 106138 & 118065 & 112684 & $11,24 \%$ & $6,17 \%$ \\
\hline 2010 & 109266 & 115098 & 109860 & $5,34 \%$ & $0,54 \%$ \\
\hline & & & OMYH & $6,89 \%$ & $4,21 \%$ \\
\hline
\end{tabular}

Tablo 9. Senaryolar ve yüzdelik değerleri (Scenarios and percentage values)

\begin{tabular}{|c|c|c|c|c|c|}
\hline & GSYH & İthalat & İhracat & Bina Yüzölçümü & Taşıt sayısı \\
\hline Düşük Senaryo & $3,70 \%$ & $9,10 \%$ & $9,30 \%$ & $1,20 \%$ & $6,90 \%$ \\
\hline Beklenen Senaryo & $4,80 \%$ & $15,80 \%$ & $15,20 \%$ & $6,10 \%$ & $8,60 \%$ \\
\hline Yüksek Senaryo & $5,90 \%$ & $22,50 \%$ & $21,10 \%$ & $11,10 \%$ & $10,30 \%$ \\
\hline
\end{tabular}


Tablo 10. Senaryolara göre SSYSA-1 tahmin değerleri(SSYSA-1 forecasting values for all scenarios)

\begin{tabular}{|c|c|c|c|}
\hline Yllar & Düşük Senaryo (TEP) & Beklenen Senaryo (TEP) & Yüksek Senaryo (TEP) \\
\hline $\mathbf{2 0 1 1}$ & 113934 & 115791 & 117312 \\
\hline $\mathbf{2 0 1 2}$ & 117258 & 120919 & 124210 \\
\hline $\mathbf{2 0 1 3}$ & 120636 & 126169 & 131315 \\
\hline $\mathbf{2 0 1 4}$ & 124061 & 131517 & 138567 \\
\hline $\mathbf{2 0 1 5}$ & 127529 & 136943 & 145896 \\
\hline $\mathbf{2 0 1 6}$ & 131032 & 142419 & 153225 \\
\hline $\mathbf{2 0 1 7}$ & 134563 & 147917 & 160480 \\
\hline $\mathbf{2 0 1 8}$ & 138115 & 153409 & 167602 \\
\hline $\mathbf{2 0 1 9}$ & 141679 & 158870 & 174554 \\
\hline $\mathbf{2 0 2 0}$ & 145248 & 164281 & 181330 \\
\hline $\mathbf{2 0 2 1}$ & 148813 & 169631 & 187939 \\
\hline $\mathbf{2 0 2 2}$ & 152366 & 174918 & 194391 \\
\hline $\mathbf{2 0 2 3}$ & 155899 & 180158 & 200649 \\
\hline $\mathbf{2 0 2 4}$ & 159404 & 185375 & 206597 \\
\hline $\mathbf{2 0 2 5}$ & 162875 & 190609 & 212024 \\
\hline
\end{tabular}

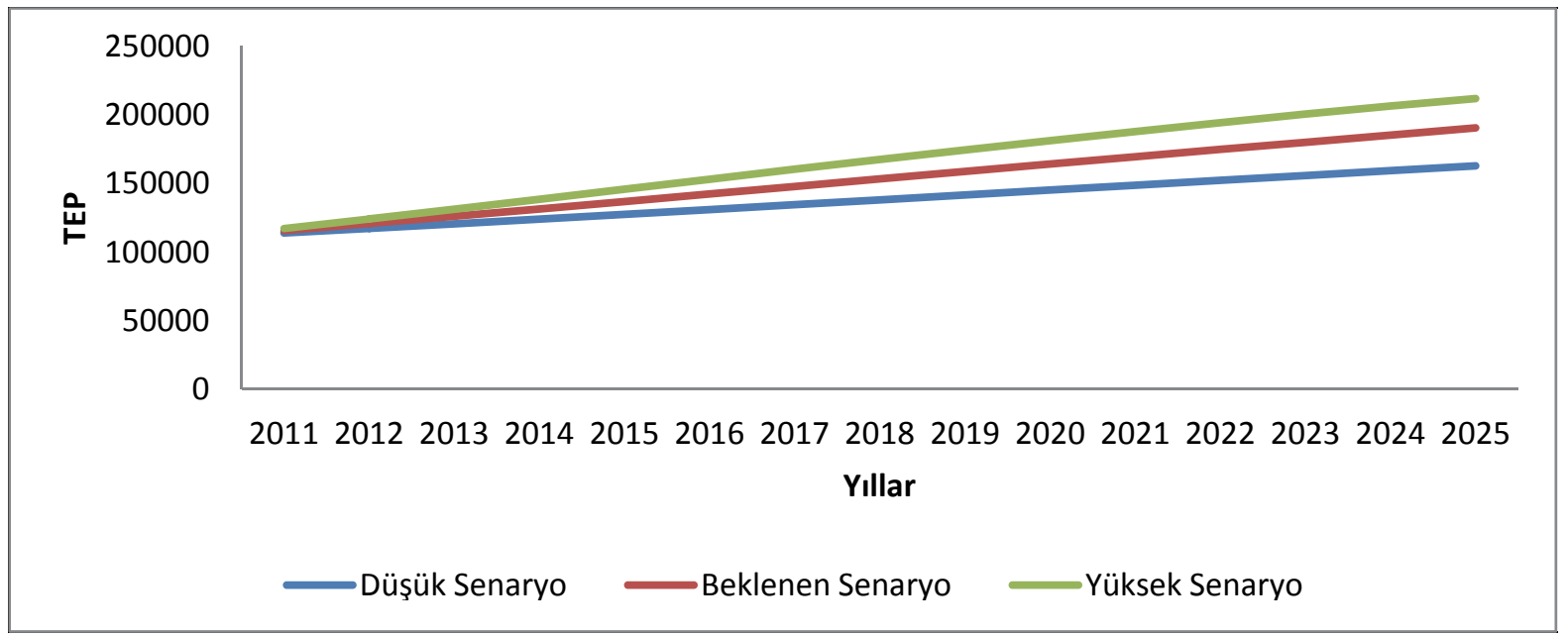

Şekil 7. Senaryolara göre SSYSA-1 tahmin grafiği(SSYSA-1 forecasting graph for all scenarios)

\section{SONUÇ (CONCLUSION)}

Stratejik öneminden dolayı Türkiye'de enerji ile ilgili farklı çalışmalar gerçekleştirilmektedir [46-50]. Bu çalışmada ise YSA ile Türkiye net enerji talebini tahmin etmek için literatürde sıkça kullanılan değişkenlere ek olarak enerji talebine etki edebilecek farklı değişkenler araştırılmıştır. Tahmin çalışmasının başarısını değerlendirebilmek ve performansını ölçebilmek için belirlenen değişkenler ile regresyon ve zaman serisi modelleri geliştirilmiş ve önerilen YSA modeli ile karşılaştırmalar yapılmıştır. Ayrıca bu çalışmada literatürden farklı olarak kullanılan bina yüzölçümü ve taşıt sayısı girdi değişkenlerinin tahmin performansını artırmada etkili oldukları görülmüștür. Yapılan analizler ve karşılaştırmalar neticesinde önerilen YSA modelinin kabul edilebilir ve yüksek doğrulukta tahminler gerçekleştirebildiği saptanmıştır ve bu modelle, 2011-2025 yılları için Türkiye net enerji talebi tahmin edilmiştir.
Gelişen ve gelişmekte olan bir ülke için enerji talebini sürdürülebilir şekilde karşılayabilmek oldukça önemlidir. $\mathrm{Bu}$ nedenle geleceğe yönelik güvenilir enerji talep tahminlerine ihtiyaç duyulmaktadır. Tahmin çalışmaları gelecek yatırımların yönlendirilmesinde, enerji politikalarının belirlenmesinde, sanayi sektörünün çalışabilirliğinde oldukça önemli olduğundan, karar vericilerin farklı tahmin çalışmalarını göz önünde bulundurarak karar vermeleri gerekmektedir. Bu çalışmanın sonuçları, başta Türkiye Enerji ve Tabii Kaynaklar Bakanlığı olmak üzere enerji üretimi ile ilgili bütün kurumları ilgilendirmektedir. Elde edilen tahmin değerleri uzun dönemli ve kararlı enerji politikalarının belirlenmesinde yardımcı olacaktır.

Gelecek çalışmalarda; enerji talebini etkileyen farklı değişkenler araştırılarak, geleceğe yönelik uzun dönemli ve kararlı tahmin çalışmaları gerçekleştirilecektir. 


\section{KAYNAKLAR (REFERENCES)}

1. Türkiye İstatistik Kurumu, "İstatistik Göstergeler 1923-2010”, Ankara, 2011.

2. Türkiye Cumhuriyeti Enerji ve Tabii Kaynaklar Bakanlığı, "2011 Y1lı Faaliyet Raporu", Ankara, 2012.

3. Türkiye Cumhuriyeti Enerji ve Tabii KaynaklarBakanlığı'“Enerji”http://www.enerji.go v.tr/index.php?sf=webpages\&b=enerii, 2013.

4. Hamzaçebi, C., Yapay Sinir Ăgları: Tahmin Amaçlı Kullanımı Matlab ve NeurosolutionUygulamalı, Ekin Yayınevi, Bursa, 2011.

5. Himanshu, A.A. ve Lester, C.H., "Electricity demand for Sri Lanka: a time series analysis", Energy, Cilt 33, No 5, 724-739, 2008.

6. Akay, D. ve Atak, M., "Grey prediction with rolling mechanism for electricity demand forecasting of Turkey", Energy, Cilt 32, No 9, 1670-1675, 2007.

7. Bessec, M. ve Fouquau, J., "The non-linear link between electricity consumption and temperature in Europe: a threshold panel approach" Energy Economics, Cilt 30, No 5, 2705-2721, 2008.

8. Wang, J., Zhu, S., Zhang, W. ve Lu, H., "Combined modeling for electric load forecasting with adaptive particle swarm optimization" Energy, Cilt 35, No 4, 1671-1678, 2010.

9. Lee, Y.S. ve Tong, L.I., "Forecasting energy consumption using a grey model improved by incorporating genetic programming", Energy Conversion and Management, Cilt 52, No 1, 147-152, 2011.

10. Küçükali, S. ve Barış, K., “Turkey’s short-term gross annual electricity demand forecast by fuzzy logic approach", Energy Policy, Cilt 38, No 5, 2438-2445, 2010.

11. Hamzaçeb,i C., “Forecasting of Turkey's net electricity energy consumption on sectoral bases",Energy Policy, Cilt 35, No 3, 2009-2016, 2007.

12. Suganthi, L. ve Samuel, A.A," Energy models for demand forecasting-A review", Renewable and Sustainable Energy Reviews, Cilt 16, No 2, 1223-1240 2012.

13. Sözen, A., Arcaklıŏlu, E. ve Özkaymak, M., “Turkey's net energy consumption", Applied Energy, Cilt 81, No 2, 209-221, 2005.

14. Sözen, A. ve Arcaklığlu, E.," Prediction of net energy consumption based on economic indicators (GNP and GDP) in Turkey", Energy Policy, Cilt 35, No 10, 4981-4992, 2007.

15. Pao, H.T., "Comparing linear and nonlinear forecasts for Taiwan's electricity consumption", Energy, Cilt 31, No 12, 2129-2141, 2006.

16. Kavaklığlu, K., Ceylan, H., Öztürk, H.K. ve Canyurt, O.E., "Modeling and prediction of Turkey's electricity consumption using Artificial
Neural Networks", Energy Conversion and Management, Cilt 50, No 11, 2719-2727, 2009.

17. Geem, Z.W. ve Roper, W.E., "Energy demand estimation of South Korea using artificial neural network", Energy Policy, Cilt 37, No 10, 40494054, 2009.

18. Ekonomou, L., "Greek long-term energy consumption prediction using artificial neural networks", Energy, 35 : 512-517 (2010).

19. Limanond, T., Jomnonkwao, S. ve Srikaew, A.," Projection of future transport energy demand of Thailand", Energy Policy, Cilt 39, No 5, 27542763, 2011.

20. Kankal, M., Akpınar, A., Kömürcü, M.İ. ve Özşahin, T.Ş., "Modeling and forecasting of Turkey's energy consumption using socioeconomic and demographic variables“, Applied Energy, Cilt 88, No 5, 1927-1939, 2011.

21. Geem, Z.W., "Transport energy demand modeling of South Korea using artificial neural network", Energy Policy, Cilt 39, No 8, 4644-4650, 2011.

22. Bilgili M., Şahin B., Yaşar A. ve Şimşek E., "Electric energy demands of Turkey in residential and industrial sectors", Renewable and Sustainable Energy Reviews, Cilt 16, No 1, 404414, 2012.

23. Ceylan, H. ve Öztürk, H.K., "Estimating energy demand of Turkey based on economic indicators using genetic algorithm approach" Energy Conversion and Management, Cilt 45, No 1516, 2525-2537, 2004.

24. Hamzaçebi, C. ve Kutay, F.," Yapay Sinir Ağları İle Türkiye Elektrik Enerjisi Tüketiminin 2010 Yilına Kadar Tahmini”, Journal of The Faculty of Engineering and Architecture of Gazi University, Cilt 19, No 3, 227-233 2004.

25. Sözen, A., Arcaklığlu, E. ve Özalp, M., "Estimation of solar potential in Turkey by artificial neural networks using meteorological and geographical data", Energy Conversion and Management, Cilt 45, No 18-19, 3033-3052, 2004.

26. Öztürk, H.K., Ceylan, H., Hepbaşlı, A. ve Utlu, Z., "Estimating petroleum exergy production and consumption using vehicle ownership and GDP based on genetic algorithm approach", Renewable and Sustainable Energy Reviews, Cilt 8, No 3, 289-302, 2004.

27. Haldenbilen, S. ve Ceylan, H., "Genetic algorithm approach to estimate transport energy demand in Turkey" Energy Policy, Cilt 33, No 1, 89-98, 2005.

28. Ediger, V.Ş., Akar, S. ve Uğurlu, B., "Forecasting production of fossil fuel sources in Turkey using a comparative regression and ARIMA model", Energy Policy, Cilt 34, No 18,3836-3846, 2006.

29. Murat, Y.S. ve Ceylan, H., "Use of artificial neural networks for transport energy demand modeling", Energy Policy, Cilt 34, No 17, 31653172, 2006. 
30. Ediger, V.Ş. ve Akar, S., "ARIMA forecasting of primary energy demand by fuel in Turkey" , Energy Policy, Cilt 35, No 3, 1701-1708, 2007.

31. Erdoğdu, E., "Electricity demand analysis using cointegration and ARIMA modelling: A case study of Turkey",Energy Policy, Cilt 35, No 2, 1129-1146, 2007.

32. Toksarı, M.D., "Ant colony optimization approach to estimate energy demand of Turkey", Energy Policy, Cilt 35, No 8, 3984-3990, 2007.

33. Canyurt, O.E. ve Öztürk, H.K., "Application of genetic algorithm (GA) technique on demand estimation of fossil fuels in Turkey", Energy Policy, Cilt 36, No 7, 2562-2569, 2008.

34. Ünler, A., "Improvement of energy demand forecasts using swarm intelligence: The case of Turkey with projections to 2025", Energy Policy, Cilt 36, No 6, 1937-1944, 2008.

35. Toksar1, M.D., "Estimating the net electricity energy generation and demand using the ant colony optimization approach: Case of Turkey", Energy Policy, Cilt 37, No 3, 1181-1187, 2009.

36. Çınar, D., Kayakutlu, G. ve Daim, T., "Development of future energy scenarios with intelligent algorithms: Case of hydro in Turkey", Energy, Cilt 35, No 4, 1724-1729, 2010.

37. Demirel, Ö., Kakilli, A. ve Tektaş, M., "Anfis ve Arma Modelleri İle Elektrik EnerjisiYük Tahmini", Journal of The Faculty of Engineering and Architecture of Gazi University., Cilt 25, No 3, 601-610, 2010.

38. Erdoğdu, E., "Natural gas demand in Turkey", Applied Energy, Cilt 87, No 1, 211-219, 2010.

39. Filik, Ü.B., Gerek, Ö.N. ve Kurban, M., "A novel modeling approach for hourly forecasting of longterm electric energy demand", Energy Conversion and Management, Cilt 52, No 1, 199-211, 2011

40. Kavaklığlu, K., "Modeling and prediction of Turkey's electricity consumption using Support Vector Regression”, Applied Energy, Cilt 88, No 1, 368-375, 2011.
41. Dilaver Z. ve Lester C. H., "Industrial electricity demand for Turkey: A structural time series analysis", Energy Economics, Cilt 33, No 3, 426436, 2011.

42. Kıran, M.S., Özceylan, E., Gündüz, M. ve Paksoy, T.,"A novel hybrid approach based on Particle Swarm Optimization and Ant Colony Algorithm to forecast energy demand of Turkey", Energy Conversion and Management, Cilt 53, No 1, 7583, 2012

43. Fausett, L., Fundamentals of Neural Networks, 3, Prentice-Hall, New Jersey, 1994.

44. Zhang, G., Patuwo, B.E. ve Hu, M.Y., "Forecasting with Artificial Neural Networks:The State of the Art", International Journal of Forecasting, Cilt 14, No 1, 35-62, 1998.

45. Lin, C.T. ve Hsu, P.F., "Forecast of non-alcoholic beverage sales in Taiwan using the grey theory", Asia Pacific Journal of Marketing and Logistics, Cilt 14, No 4, 3-12, 2002.

46. Kabak, M. ve Dağdeviren, M., "Prioritization of renewable energy sources for Turkey by using a hybrid MCDM methodology", Energy Conversion and Management, Cilt 79, 25-33, 2014.

47. Yüksel, İ., "Global warming and environmental benefits of hydroelectric for sustainable energy in Turkey", Renewable and Sustainable Energy Reviews, Cilt 16, No 6, 3816-3825, 2012.

48. Hamzaçebi, C. ve Es, H.A., "Forecasting the annual electricity consumption of Turkey using an optimized grey model”, Energy, Cilt 70, 165-171, 2014.

49. Balat, M., "Security of energy supply in Turkey: Challenges and solutions", Energy Conversion and Management, Cilt 51, No 10, 1998-2011, 2010.

50. Şimşek, H.A. ve Şimşek, N., "Recent incentives for renewable energy in Turkey" Energy Policy, Cilt 63, 521-530, 2013. 